\title{
Housing infrastructure: contemporary issues in timber adoption
}

\author{
Alohan Omoregie BEng (Hons), MEng, PhD \\ Civil Engineering and the Built Environment, College of Engineering \\ and Technology, University of Derby, Derby, UK
} (corresponding author: a.omoregie@derby.ac.uk)
Mark English BSC (Eng), BSC (Arch), MA (Arch), MCIAT, IEng, MIMechE, CBuildE, MCABE

Mark English Architecture, The Grainger Suite, Newcastle Upon Tyne, UK

Scotland currently has $\mathbf{7 6 . 7 \%}$ of all implemented timber-framed buildings in the UK housing market. England's figure is $16 \%$. The English contribution is considered relatively low given its demand for more sustainable, low-cost social housing. The aim of this study is to investigate potential contemporary barriers to the adoption of timber as a primary structural material in residential housing developments in England. The research methodology is quantitative and findings revealed that a combination of economic, cultural and psychological issues rather than technical and durability performance are responsible. These are fundamentally due to lack of education regarding the use of timber, erroneously perceived increased maintenance costs of timber housing, developers' influence and monopoly over timber technology, uncertainty in property resale value and the recent overall lack of confidence in timber technology. It is recommended that improved training comprising compulsory basic timber technology and sustainable construction is adopted as a formal prerequisite for the attainment of relevant qualifications within the built environment, civil engineering and architecture. To this end, the benefits of sustainable construction, specifically, timber, in housing should be introduced even at the pre-university level, within schools and colleges. Also recommended are public awareness campaigns through relevant institutions, in the public and private sectors and among construction professionals, of the merits and misconceptions surrounding timber technology.

\section{Introduction}

There is substantial evidence to suggest that timber is one of the oldest building materials known to humanity. There is plentiful evidence to suggest that timber housing technology had evolved extensively in Europe long before $79 \mathrm{AD}$, in areas stretching across what is now Italy, France, the Netherlands, Switzerland and Germany. Of note, is the 'House of Opus Craticum' (timber framed with wattle-work infill) buried in the Mount Vesuvius eruptions in Herculaneum, Italy and timber frames with stone rubble infill on mortar referred as opus incertum in Roman times (Guy, 2006). There are still many timber-framed houses from the twelfth century still in existence today in the UK (Palmer, 2000). Aspects of this technology were exported to North America from Europe in the late twelfth century to the nineteenth century.

Notwithstanding, the historical position of pioneering timber technology in Europe and the fact that timber-framed homes made up about $27 \%$ of all new builds in the UK in 1982, their housing market share has plummeted to about $6 \%$ in recent years. This drop-in market share is not surprising following the combination of adversarial publicity concerning the structural robustness of timber-framed houses and the impact of the global financial crisis on the property market. Throughout this period, the proportion of timber-framed construction in Scotland was $40-45 \%$ of all newly built property (Palmer, 2000); a very different proportion to that seen in England, Ireland and Wales. Notwithstanding the inherent economic, aesthetic, technical and environmental advantages timber-framed buildings present to contemporary housing infrastructure in the UK, there is still some subtle contemporary misperception to the adoption of timber-framed housing particularly in England. Notable, among these advantages, are rapid production (modular construction, prefabrication and mass production), flexibility, running costs and seismic-impact reduction. The other advantages being robustness, energy efficiency, embodied energy, carbon dioxide emissions, air tightness, acoustic performance, fire performance and durability compared with other building materials like masonry (Dinwoodie, 2010; Palmer, 2000; Taylor, 2000).

Common misguided perceptions of timber-framed buildings in England range from the flawed opinion of timber's fire resistance to robustness: the 'mechano-sorptive-creep syndrome' (Hoffmeyer and Davidson, 1989; Strombro and Gudmondson, 2008), where structural members in service absorb moisture resulting in its irreversible deformation, often slanting several degrees from its original position, making it unsafe, unstable and costly, susceptibility to insects, poisonous black mould, rot and bacterial decomposition. Although these perceptions are 
misguided and based on the incorrect premise, particularly given the standardised regulations and practice in place, these beliefs and perceptions remain within the building sub-sector and the public. Therefore, the aim of this study is to investigate contemporary potential barriers to the adoption of timber as a primary structural material in residential housing infrastructure in England. The research objectives are to investigate current opinions and perceptions of design professionals concerning the use of timber as primary structural material in England' and to identity and evaluate the main barriers to the adoption of timber as a primary structural building material within England. This paper is subdivided into five sections, and these are introduction, literature review, methodology, results and discussion, conclusions and recommendations.

\section{Literature review}

From a structural perspective, timber has an interesting property, especially considering its behaviour in the event of fire compared with steel. Under fire, a typical timber chars at about $0.5-0.7 \mathrm{~mm} / \mathrm{min}$ and charcoal (even in its apparently damaged state) holds the ability to insulate the interior of the timber member - a unique property that is absent in steel. Notwithstanding significant increases in temperature, timber still maintains its strength and geometrical properties (length, width, curvature etc.) until scorched. With steel, however, a significant increase in temperature can cause an irreversible change in structural stability, geometrical and material properties. Thus, structural members like steel beams under fire, for instance, are prone to failure due to increased thermal stresses resulting in the overturning of walls or other members they support, which can prove fatal in certain situations. So, thermally insulated timber encasement provides almost equivalent protection for steelwork as concrete would for steel under the effects of fire (Everett and Barritt, 1994). The durability of a well-seasoned timber is enormous, and there is evidence that massive structural sections $(200 \mathrm{~mm} \times 200 \mathrm{~mm}, \quad 225 \mathrm{~mm} \times 225 \mathrm{~mm}, \quad 450 \mathrm{~mm} \times 450 \mathrm{~mm})$ like those used in medieval times, when well seasoned and maintained could have a working lifespan of more than 600 years, and potentially more than 1200 years. An example is Greensted Church in Greensted-Juxta-Ongar village in Essex, England (Clive, 2005). Bearing in mind the preceding historical perspective (medieval period), it is important to introduce briefly the common forms of timber-framed systems in the UK.

Modern methods of timber construction include timberframed open and closed panels, structural insulated panels (SIP), beam-and-column or stick-built systems and timber modular systems (Gibb and Pendlebury, 2006).

In the UK, the timber structural frame system with external brickwork cladding (also known as rain screen) is very common. However, there are three main methods of timber construction in the UK. These are: hand erect (small panel), crane erect (large panel) and stick built (otherwise referred to as post and beam in the UK, but in the USA and Canada stick built, and post and beam terminologies are completely different). There are classic and very innovative products of this construction type by Huf Haus scattered all over the UK (Figures 1 and 2).

Stick-built construction is when the components are cut and prepared off-site and assembled on-site using simple hand tools. A practice quite common in Japan, Canada and the USA, but such practice (uses) is restricted to post and beam type construction in the UK (Palmer, 2000), and in the UK both terminologies (stick built, and post and beam) are

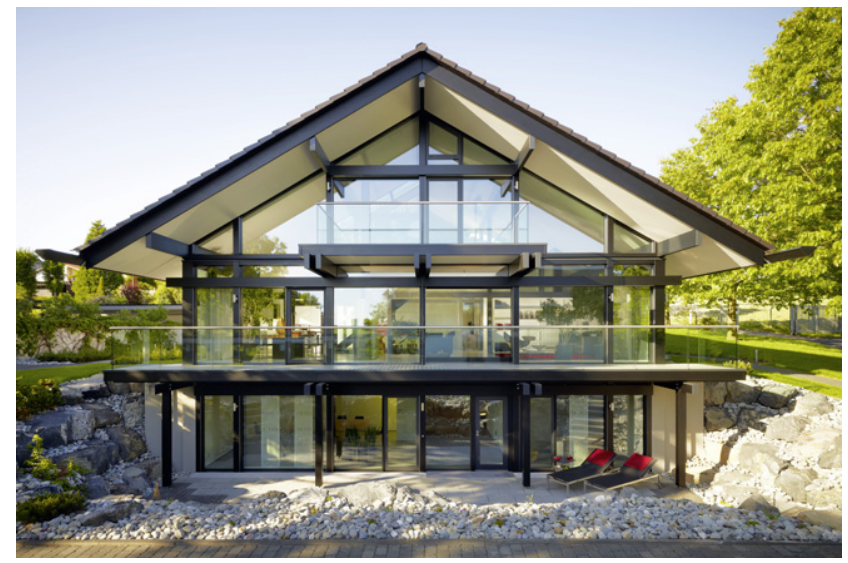

Figure 1. An example of post and beam systems (also known as stick built in the UK)

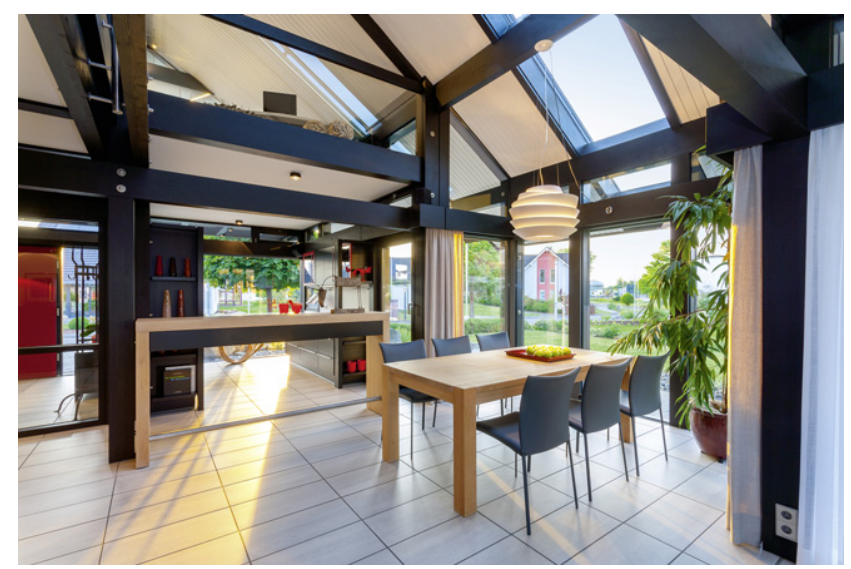

Figure 2. Timber internal finishes 
apparently interchangeable. So, timber post and beam homes are constructed using vertical structural columns and horizontal structural beams with infill framing, masonry (brick) and shear panels of different makes.

There are vast varieties of this type of construction in the UK, which is not surprising bearing in mind the development and evolution of this technology over the past 4000 years (Self Build, 2016). Post and beam are the most popular timber technology in the world; versatile for its flexibility, especially for the construction of traditional and contemporary dwellings or for a combination of both. Notably post and beam constructions are also greatly admired for its application in open-plan spaces allowing flexible internal architecture. However, multitudes of individual units are required for construction. These units, requiring hundreds of timber posts and timber beams for a single construction, can be prefabricated and assembled into a singular section in a modular fashion. This means that subsections of the timber building can be factory prefabricated and hoisted and bolted into position on-site. These, prefabricated sections (modular post and beam) reduce the number of units required for the whole building significantly. The fast pace of contemporary post and beam timber construction in the UK is one of its greatest advantages - more so given its unique architectural aesthetic character and value it presents to contemporary timber buildings (Figure 2).

This approach is low cost, and its flexibility allows easy and quick modification where necessary. It is widely believed in the UK that a simple post and beam form (using conventional softwoods for the building envelope) and cladding in timber can be far more cost effective compared with other construction methods in the UK. However, the infill for the post and beam construction has also witnessed significant and unique transformation over the years. Most common and ancient infill types in Europe are decorative fired-brick infill, ordinary brick infill and stone infill (often referred as opus incertum by Romans). Now a timber structural frame system with brickwork external cladding construction is commonplace in the UK.

Undoubtedly, timber technology has improved immensely in the UK to meet the structural and environmental challenges within the built environment, with fascinating products such as cross-laminated timber and SIPs where engineered plywood encases the rigid form insulation.

As mentioned, timber structural systems are currently used in the UK housing sector, and Scotland holds the largest share of these developments - England and Wales account for only 3\% of new constructions per annum (Mackay, 1997). Although these figures have increased slightly in recent years, traditional masonry brick-and-block construction continues to dominate the housing market within England, usually resulting in lengthy build processes and often characterised by supplementary defects from the masonry systems (Roy et al., 2003). However, it has been argued that developers are the group that chiefly influences the choice of structural system and that the quality of contemporary construction methods in England is reducing the customers' interest in other methods, and fragmented adversarial relationships often characterise these processes. Consequently, it is being proposed that the entire construction process for housing in England be reconsidered with a clear emphasis on innovation through timber structural systems (Roy et al., 2003). Also to be considered is technology offering off-site prefabrication that mitigates 'down-time' onsite through poor weather conditions and helps reduce waste through the use of automated construction that sometimes exceeds a $24 \mathrm{~h}$ production time-frame (Ozorhon, 2012, 2013; Xia et al., 2014).

As previously reiterated, increased thermal performance and the ability to comply with future, increasing thermal demands from building regulations are factors that are believed to make timber a key driver for sustainable energy-efficient construction (Dickson and Parker, 2015; Ozorhon, 2013; Xia et al., 2014). The published statistics on the use of structural timber technology assert that the industry may not have accepted timber technology - as only a small proportion of house builders choose to adopt it (Adams et al., 2009). Furthermore, in a recent survey of the top 100 UK house builders, it was revealed that there are key barriers to the adoption of timber. These include higher capital costs and the inability to achieve economies of scale (cost advantage due to increase in output) along with skill shortages both on-site and off-site (Pan et al., 2008). An earlier study also showed that the lack of adoption of structural timber technology is attributable to a shortage of skilled subcontractors with the relevant knowledge and experience of timber-frame installation on-site (Ball, 1999). There is sufficient anecdotal evidence to suggest that the skill shortage may be the by-product of main contractors and developers subcontracting out the specialist labour within the construction process resulting in reduced innovation and new skills training. It is unclear if the fragmentation of the industry has a part to play in the poor adoption of timber technology in the English housing market. It may be that a lack of collaboration between suppliers, builders and developers leads to the erroneous belief that structural timber technology is a specific specialist process (Fulford and Standing, 2014). Even with timber system manufacturers errors are sometimes noticed. However, like any production process errors can and will occur in construction or assembly causing, over time, small maintenance issues and in extreme cases catastrophic structural failure resulting in total collapse. It is important to understand that this is not peculiar to timber structures alone. However, recently modern construction systems are said to suffer from several inherent 
defects that are caused by the design process. The more serious structural failure defects are mainly due to timber degradation due to water ingress caused by poor design by architects and structural engineers (Wood, 1993).

Another recent study has shown that defects on structural elements such as walls and openings are the most commonly occurring preventable defect within timber module fabrication. This research has shown the root causes of the defects were structural design error and bad craftsmanship. Much of the defects occurred during the 2-year warranty period, with almost half of these originating from factory production where during a factory audit structural design contributed to $~ 30 \%$ of defects (Johnsson and Meiling, 2009). The structural design defects identified are a movement of the structure, severe cracking to the corners as well as the misplacement of openings and poor material choice by the architect and structural engineer. As a critical response to the research by Johnsson and Meiling (2009), several interesting issues were identified, notably whether these defects were the result of poor technical detailing (impregnation, surface coatings and seasoning) rather than purely engineering design factors.

One possible explanation that will require investigation is the potential lack of knowledge that design professionals have as regards timber technology and construction. An enquiry into the opinion and perception of those professionals involved in the technical detailing and specification of residential projects may help resolve some of these issues.

It has also been identified that there is a potential shortfall in the level of education experienced by key professionals (i.e. engineers and architects) in the timber technology field. It may be argued that formal education does not adequately deliver the skills and industry knowledge required for timber technology. Experiential learning may be considered a more rounded approach to the architectural and engineering design pedagogy. Moreover, it may be stated that the education system itself must shoulder some responsibility for the lack of formal knowledge surrounding timber technology. It should be noted that both points deserve further investigation within this study (Bayne and Taylor, 2006; O'Connor et al., 2004).

Recent research has also shown that architects consider themselves to have limited choice in material selection and are reluctant to use timber as a structural material (Mahapatra and Gustavsson, 2009). Studies suggest that structural engineers base their selection of construction material on their design knowledge and the 'tried and tested' method of the specification. It can be argued that engineers believe they are instructed by the architect to realise and supply practical structural solutions to the presented proposed design. Therefore, if timber technology is not included in the initial design, it is not considered something that the engineer may introduce, regardless of their level of knowledge/experience. This may also influence the decisions made by architects and architectural technologists in initial construction technology decisions. So, the poor level of knowledge, education and experience in timber technology could potentially inform the perceptions and attitude of architects and engineers towards it. Therefore, the level of exposure to timber construction and typical educational background of construction professionals may require investigating further in the context of timber construction as part of this study.

This literature refers throughout to previously studied opinions and perceptions of architects and engineers. The authors have recognised and identified that few, if any, studies exist establishing the opinion and perception from an architectural technologist's perspective. These professionals are one of the key agents that drive the technical specification and technology selection within the construction industry and, as such, they may hold valuable knowledge and insight on the potential barriers to timber adoption within the English housing market. Furthermore, this may be an area to expand on in study and help fill the gaps in existing knowledge through the contribution of new learning.

\subsection{Public opinion of timber construction}

Research has shown that the most important consideration in a house purchase decision is price, followed by maintenance, mortgage availability, low energy performance and finally fire performance (Hamilton-MacLaren et al., 2013). The acceptability of traditional brick-and-block construction was extremely high, as expected, with timber-frame construction receiving lower levels of acceptance. The main construction concerns are the risk of rotting and increased fire risk; however, it is acknowledged that timber construction methods produced increased levels of energy performance and reduced environmental impact (Hamilton-MacLaren et al., 2013). A survey of the UK timber construction industry identifies a lack of public support and poor market demand as the main reasons for limited expansion (Venables et al., 2003).

Overall, it seems that there is a negative public opinion about timber construction in the UK. Perceived barriers regarding public opinion in the use of timber technology are highlighted as follows.

- Expense - timber construction is perceived as higher in cost compared with traditional brick-and-block construction.

- Durability - that it is somehow inferior regarding long-term strength and robustness.

- Fire risk - increased fire risk as raw timber is combustible. 
It appears that the public's perception of timber construction is that of an inferior technology when compared with that of traditional building and that it, therefore, should be saved for the social housing sector, implying a negative sociocultural status towards timber ownership.

Due to its high thermal resistivity, timber feels warmer to the touch than other construction materials such as steel or concrete at similar temperatures making it ideal for internal property fittings such handrail and doors. As a result of this and the tactile, environmental and nontoxic properties of wood or timber, when used in construction, it has developed a certain amount of high social desirability (Zobel, 1984). It may account for the reason why historical residential properties with large oak beams and timber cruck-frame construction are at a premium in the UK.

However, as previously discussed this is not the case for modern structural timber technology and is borne out through a lack of adoption. It may be observed that modern properties have brick facades and are almost attempting to convince and mislead the public that they are traditionally constructed. This opinion, along with other negative views, has been sensationalised by the UK national press following a series of construction fires with one such newspaper article from The Telegraph (2002). Explaining the additional dangers of timberframe home ownership in increased risk of rotting structures, increased fire hazards due to faulty wiring in cavity walls and cheaper, quicker construction methods that ensure greater profit margins for the developer, many other articles report similar cynical views of failures in structural timber technology with some of the publications supported and used by brickand-block manufacturers to promote the benefits of their products and construction methods (BBC, 2010; The Telegraph, 2002). While it is recognisable that these publications are not academic or professional sources, it is obvious that they may influence or illustrate the possible sociocultural influences of mainstream media over public opinion.

This negative press along with a lack of accurate information and knowledge concerning structural timber technology certainly leads to strong public prejudice against its use in housing construction (Wang et al., 2014). This prejudice is further exacerbated subconsciously by the fact that timber is often perceived as fuel for the fire and with the perception of brick-and-block construction being somehow superior regarding strength and robustness. This erroneous perception of timber is very recent and has helped brick-and-block construction to become the culturally accepted norm and lightweight alternative building materials to be substandard and of lower quality. This perception also influences the conservative opinions of mortgage lenders and insurance underwriters, holding back construction innovation (Levander and Sardén, 2009) more than likely due to their pessimistic outlook and evaluation of risk or uncertainty. Surprisingly, there are cases where homeowners have failed to obtain mortgage lending and finance along with adequate insurance cover due to their home being constructed with timber as the primary structural material (Toratti, 2008). One of UK's largest insurance brokers, currently states on its website that 'some insurers perceive timber-framed buildings as being more vulnerable to fire, which means some might not be able to provide cover and others may charge a higher premium' (GoCompare, 2015). There are attempts being made by the UK government and the timber supply industry to counteract negative public opinion with the introduction of various initiatives that promote timber in construction by educating the public and associated professionals (Wang et al., 2014).

The literature underlines key barriers to timber technology adoption in English housing and these are listed as follows.

- Higher costs - both in design and construction over traditional brick-and-block construction.

- Durability issues and water ingress - timber rotting.

- Increased fire risk - both in construction and once built.

- Lack of formal education within design and engineering.

- Overall negative public perception.

These, along with sociocultural influences - labelling timber as an inferior technology - again, may have caused adoption issues in housing within England.

\section{Methodology}

The literature review has been used to identify and highlight deficiencies and relevant factors impeding the adoption of timber technology in the English housing market sector. These factors or theories established in the literature review were then tested in a fieldwork survey using a questionnaire data collection tool. The fieldwork survey was essentially quantitative research. Questionnaires are the most common method of collecting factual evidence and are often used to establish a quick 'snapshot' of data (Farrell, 2011). Questionnaires are, however, also subject to academic criticism in that poorly structured examples may result in unreliable data - failing to measure the respondents' validity and suitability (Creswell, 2003; Farrell, 2011). This type of research was used, however, because it is the aggregate perception of views about the research aim and objectives required in this study.

Following the comprehensive literature review, it appears that the key professionals influencing the timber adoption decisionmaking process in the built environment are principally architects and architectural technologists. Their perception is enforced by the opinions of engineers and other construction 
professionals. Although several studies exist that establish the opinion of architects, very little is known from the position of the architectural technologist as key drivers in the design and selection of the structural timber technology. Therefore, architectural technologists (practicing in England) are the key respondents in this study. The research findings can be inferred anecdotally for the whole of the UK although $21 \%$ of respondents indicated that they are not involved in the design of residential housing in the UK. Therefore, generalisation must be implied with some care bearing in mind that the analytical tools used for this study are not inferential but descriptive in nature and the fact that a sizeable majority of respondents are in the UK (specifically England).

The sampling strategy adopted was simple random sampling with a sample size of 100 respondents.

The estimated sample size of 100 was adopted in line with published sample size tables (Israel, 2013); with a specified precision level (sampling error) of $10 \%$ (i.e. the assumed proportion difference between the sample and the actual population values or characteristics). Sampling errors are usually assumed or statistically speculated bearing in mind the impracticality to measure the actual population values/characteristics in any research. However, sample error (caused by sampling bias) can be reduced and controlled if the right sampling technique and the sample size are adopted. The sample size was estimated at a confidence interval or risk level of $95 \%$ and degree of variability 0.5 using the following relationship

$$
n=\frac{N}{1+N(e)^{2}}
$$

where $n$ is the sample size, $N$ is the population size and $e$ is the level of precision (sampling error); the degree of variability of $0 \cdot 5$ is assumed.

It is also important to make clear that $95 \%$ confidence interval or level simply relates to the 'reliability of the estimated procedure' and not the speculated or assumed interval (with the population characteristics) as erroneously widely published in statistical studies. The initiator of 'confidence interval' Neyman (1937) in the study of the 'theory of statistical estimation based on the classical theory of probability' confirms very clearly that confidence interval relates only to the estimated procedure.

The level of precision (e) defines the estimated range of the true value of the population frequently conveyed in percentage points (e.g. $\pm 10 \%$ ). For example, if $60 \%$ of doctors in the sample adopt a recommended practice with a precision rate of $\pm 10 \%$, then one can statistically infer that between 50 and $70 \%$ of doctors in the study population have adopted the practice.
The proportion of 0.5 indicates the maximum variability in a population; it is often used conservatively to determine the sample size, that is, the sample size in use may be larger than if the true variability of the population attribute were used.

It is interesting to mention that almost a $100 \%$ response rate was achieved. The $100 \%$ response rate may appear unrealistic to many practitioners or researchers within the built environment. However, this is not impossible within statistics. Responses to any surveys are very often driven by interests, especially the topical nature of the research subject, ease of responding to the questions and the way the data collection tool (questionnaire) is administered. The survey was conducted online with the help of the Chartered Institute of Architectural Technologist (CIAT) whose membership the second author currently enjoys. However, the selection of respondents was completely outside the authors' influence to achieve an unbiased representation of the study population.

This sampling strategy was adopted to provide an equal and independent chance of selecting an unbiased sample (Kumar, 2014). The sample space (proposed study population) was made up of practicing professionals, specifically, architectural technologists.

The identity of the respondents was protected, and they were asked to respond by completing an electronic multiple choice questionnaire with their participant Internet Protocol address being logged to prevent duplication, corruption and falsification of electronic data. Random sampling was carried out through the contact details of individuals working within the geographical area from the CIAT.

\subsection{Questionnaire}

The structured questionnaires were implemented to identify the age, profession, educational history and geographic location of respondents. Besides, the questionnaire captured the current design practice data establishing the level of knowledge and opinion of respondents as regards timber technology within the English housing sector. The questionnaire consisted of ten questions which were modified through a pilot study with several containing multiple elements to establish and maximise the collected data. Figure 3 shows how the questions were mapped against the research aim and objectives - that is, which of the questions addresses specific research objectives.

- Justification of question 1: To establish the primary profession of the respondent. This is fundamental to establish the role and level of integration within the design process and decision-making responsibility.

- Justification of question 2: To identify the age of the subject for demographic purposes. This assists in establishing the level of experience within the respondent's profession. 


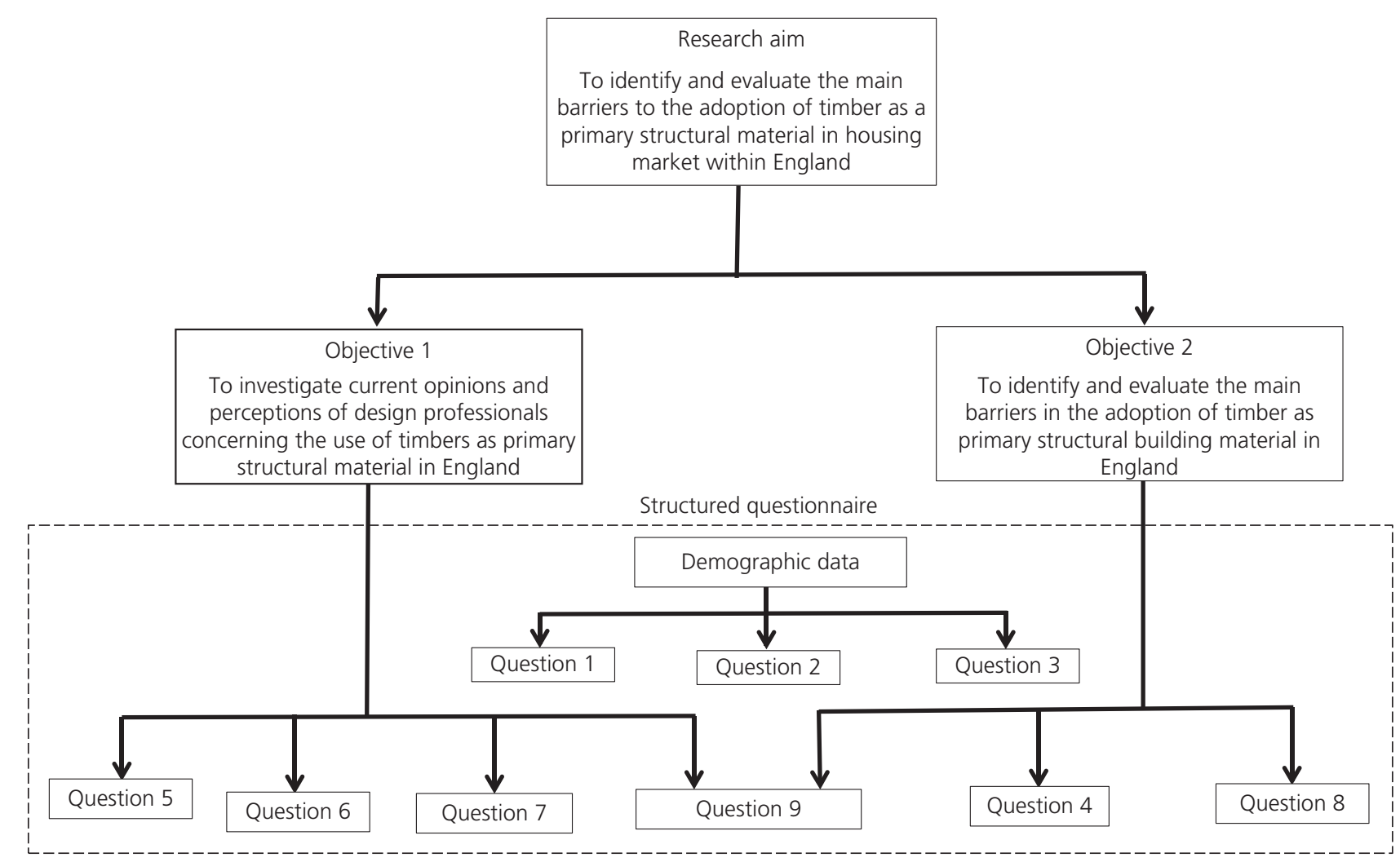

Figure 3. Research questions mapped against aim and objectives

- Justification of question 3: To indicate the highest level of education. This assists in establishing the level of knowledge within the respondent's profession.

- Justification of question 4: To highlight the training received either within formal education and workplace learning and training. This tests the theory that a potential shortfall in formal education experienced by key professionals within the area of timber technology adds to a lack of adoption of the technology (O'Connor et al., 2004). Bayne and Taylor (2006) also highlight this by identifying that a level of self-education would be required for the implementation of timber construction projects.

- Justification of question 5: To test the theory that recent findings suggest that the 'tried and tested' method of the specification is preferred over traditional masonry construction selected by default over timber technology (Hamilton-MacLaren et al., 2013).

- Justification of question 6: To establish the respondent's involvement in housing design and determine if timber technology has been implemented.

- Justification of question 7: To investigate the perceived roles within the structural specification of housing as regards the selection of structural material.
- Justification of question 8: To test the theory that additional dangers are present in timber-frame home ownership with increased risk of structure rotting; increased fire hazards, architects' and engineers' understanding of a possible lack of timber and the perceived influence that mortgage lenders have over structural technology selection (GoCompare, 2015).

- Justification of question 9: To test if architectural technologists agree with architects and engineers in that the barriers to timber adoption are attributed to sound transmission issues, poor form stability and movement, and material decay. Architects and engineers have also cited timber as an unknown technology with many individuals experiencing a lack of practical work knowledge.

- Justification of question 10: This data is not to be included in this study. However, it will be used for the next publication or further research in this area.

\section{Results and discussion}

The presentation of the data was undertaken using descriptive statistics and findings extrapolated with the aid of frequency counts. Basic demographic data (about the respondents) was 
collected to establish the age range of respondents. It may be observed, as in Figure 4, that there were fewer respondents at the lower and upper age limits, namely 29 years or younger and 60 years or older, with most respondents aged between

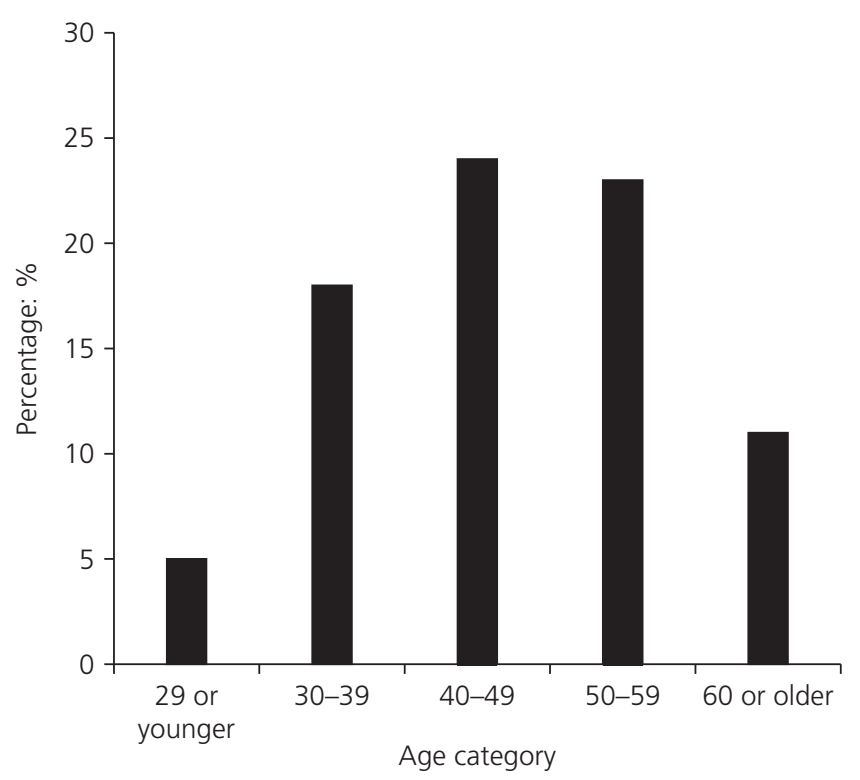

Figure 4. Respondents' age category
30 and 59 years. Furthermore, the distribution of the age category in Figure 4 is almost symmetrical (i.e. very close to a normal distribution), which gives some credence to the spread of responses among the age category/groups. It can, therefore, be inferred that majority or some of the respondents has several years of current professional experience which also provides some level of validity to the research data.

Figure 4 data was scrutinised further with the addition of a further request for the educational information or background of respondents. It can be seen from Figure 5 that an additional dimension to the age demographics was achieved by introducing data detailing the respondents' highest completed educational qualification.

\subsection{Respondents timber design education}

From the chart (Figure 5) it is observed that younger individuals (aged 29 years or younger and in the range 30-39 years) have formal undergraduate education. Those in the 40-year plus age range (40-49,50-59 and 60 years or older) have a large percentage of professional qualifications (assumed without formal university education). This extrapolates to $56 \%$ of the respondents aged 39 years or younger holding an undergraduate degree as their highest qualification, with $69 \%$ of the 40 years plus and above age range holding professional qualifications as their highest achievement. It should also be noted that postgraduate qualifications (in $25 \%$ of respondents) are

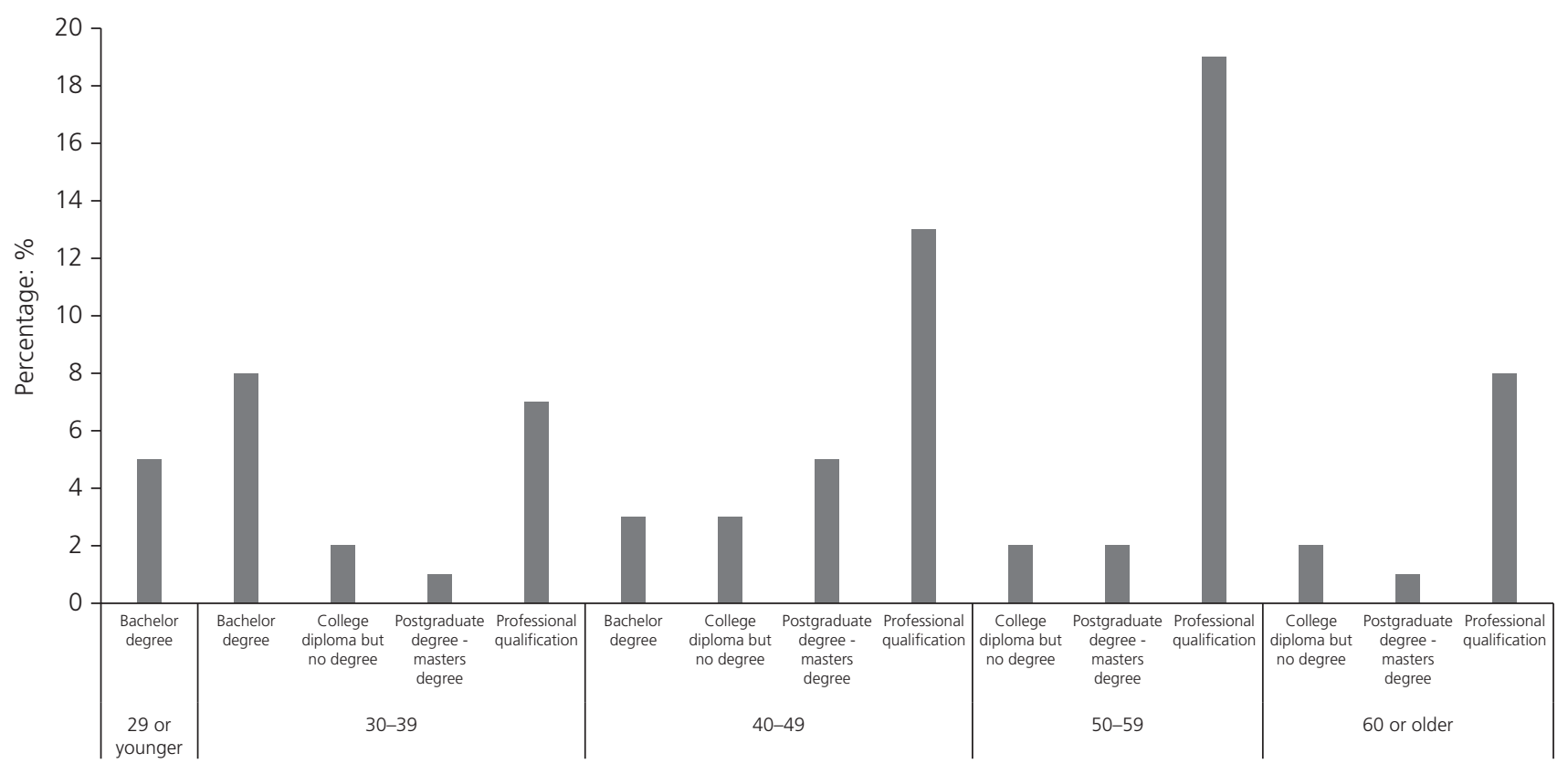

Respondents' highest completed qualifications by age category

Figure 5. Age category and highest completed qualification 
spread over the entire age range outside the lowest limit (29 years or younger) with a peak distribution at 40-49 years. On close examination of the data in Figure 5, some level of disparity in the highest completed qualification within the age groups can be discerned. Professional qualifications appear to be negatively skewed (or skewed to the left) following the increase in the age category of the respondent (i.e. with the long tail on the negative side of the graph's peak). At the same time, academic qualification is positively skewed or skewed to the right (i.e. in the long tail of the normal distribution on the positive side of the graph's peak value (per cent)) with a decrease in the age category of respondents. This data clearly presents the unhealthy dichotomy between academic and professional recognition with respect to age, type of qualifications and practical experience. The controversy this presents in the $\mathrm{UK}$ professional practice is considerable. While it is not the intention of this study to dwell on these issues, nonetheless, where age presents a clear division or distinction in professional recognition, it should be discouraged and often subtle indications of 'false protectionism' or discriminatory categorisation. Such are an unhealthy and clear aberration to smooth and effective practice. However, the blend in professional and educational attainment gives further credence to the spread of respondents in this research.

Having established the age range and educational background of the respondents, investigating where these respondents gained their knowledge of timber technology would also be essential. Figure 6 shows that a large proportion (45\%) gained their experience and knowledge through workplace learning and training. This data appears to agree with the literature that suggested a high degree of workplace learning and selfeducation.

However, it should also be highlighted that only $8 \%$ achieved timber design knowledge through their undergraduate education studies and 3\% through postgraduate education. This development is rather surprising given the fact that of the

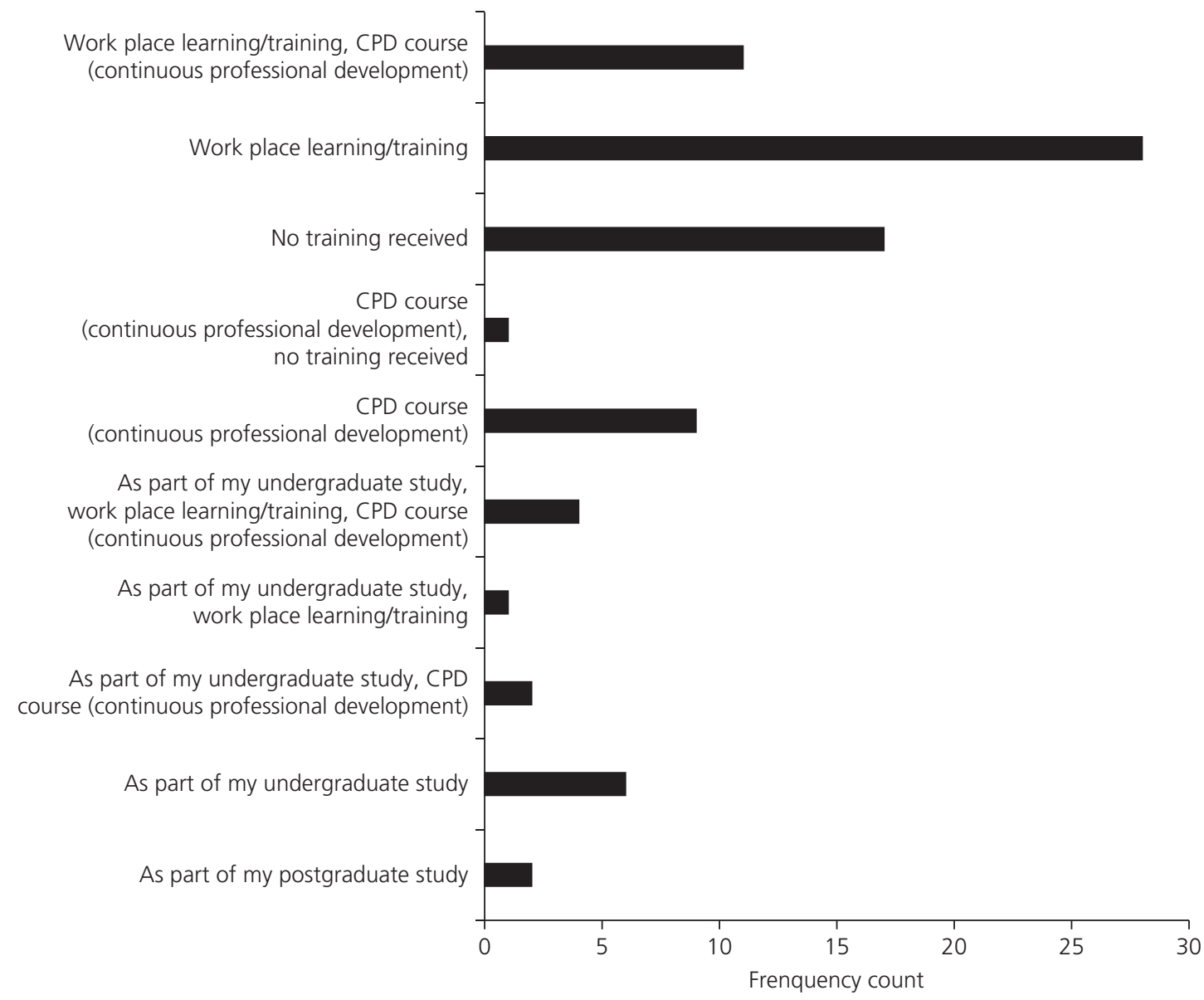

Figure 6. How respondents studied timber technology (design) 
20 respondents experiencing a formal university education, only $40 \%$ undertook timber technology design (i.e. eight out of 100 respondents). Interestingly, only $45 \%$ of the total study population indicated that they received workplace learning in timber technology with only $30 \%$ experiencing no training at all. Given this data, further investigation was carried out to establish if local universities and colleges delivered timber technology design as part of their undergraduate and postgraduate programmes. From the learning establishments contacted only four courses $(15 \%)$, at undergraduate and postgraduate levels, were identified from a possible 26 within the north of the UK offering timber design. However, it must be noted that of these four courses teaching timber technology, all the universities were geographically located in Scotland. Therefore, it may be

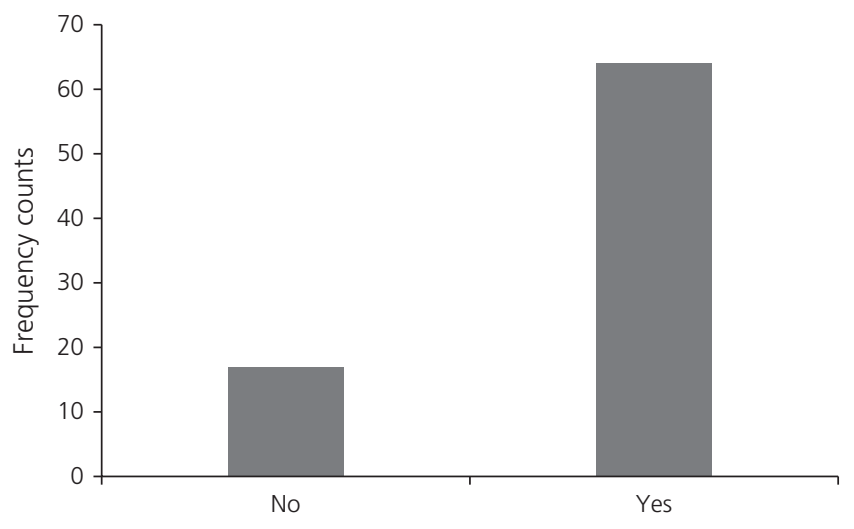

Involvement in residential housing design

Figure 7. Respondent involvement in residential housing design tentatively stated that this may account for the shortfall in design education within timber technology as described by Bayne and Taylor (2006).

\subsection{Recommended structural method in housing}

A key question (on whether respondents are involved in the design of residential housing in England) was posed to all respondents, the results of which are indicated in Figure 7. A large percentage $(79 \%)$ of respondents indicated that they are involved in the design of residential housing in England. This small piece of information adds a huge amount of credibility to the answer that a large portion of the surveyed (respondents) work within the residential housing infrastructure market.

However, from the study population, only $22 \%$ would recommend timber technology as the primary structural solution for residential housing in England (presented in Figure 8). From Figure 8, 69\% of architectural technologists would rather recommend traditional construction regarding the brickand-block method as the most commonly recommended construction solution within England for housing projects. This agrees with the study by Roy et al. (2003) where they state that traditional masonry brick-and-block construction dominates the housing market within England.

These findings (Figure 8) may seem more surprising as further data was acquired (Figure 9(a)), establishing that 91\% of architectural technologists were aware of the environmental benefits of timber technology within housing projects; yet it was not recommended. Moreover, $62 \%$ of architectural technologists

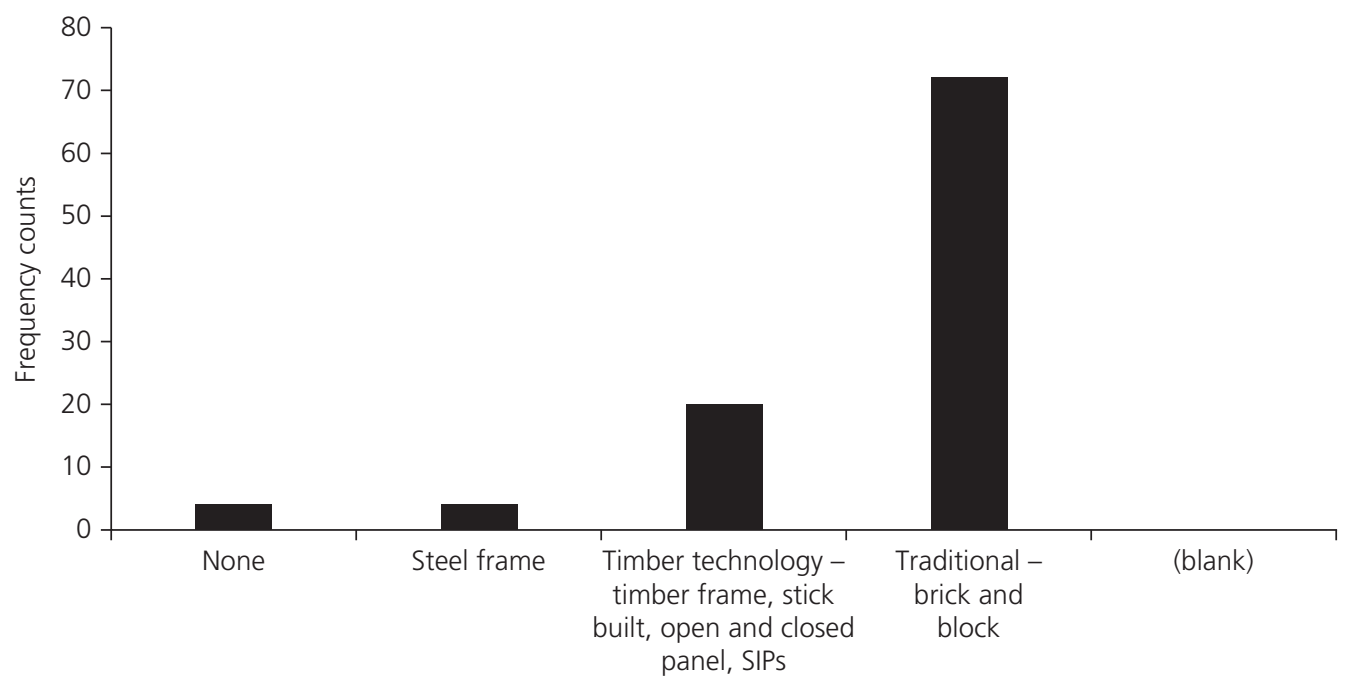

Figure 8. Most recommended construction method for residential housing 


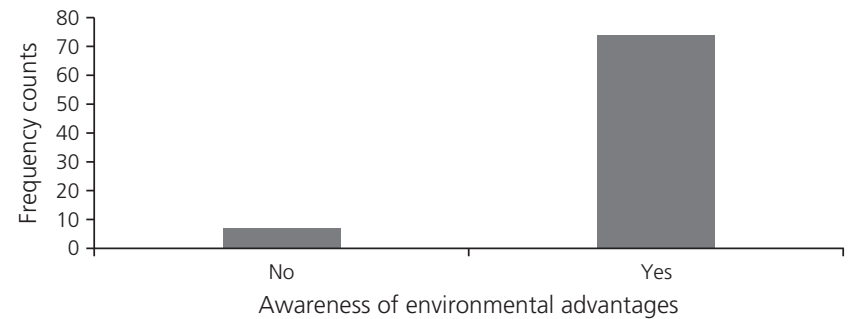

(a)

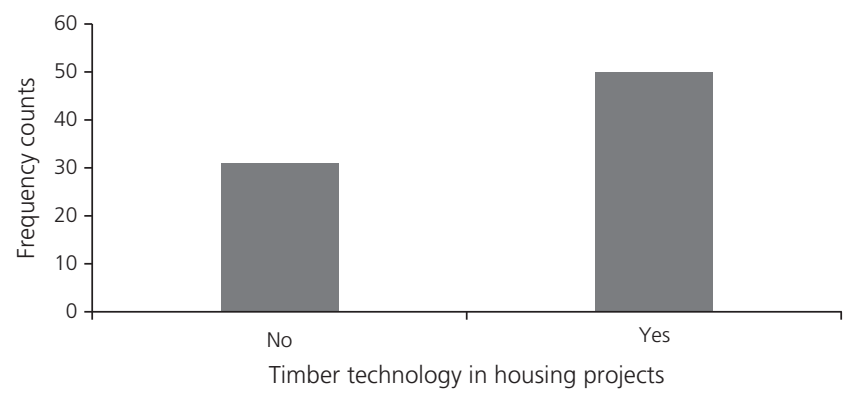

(b)

Figure 9. (a) Awareness of the environmental advantages in timber technology. (b) Implementation of timber technology in respondents housing projects

have had timber technology implemented on a project in which they have been directly involved (Figure 9(b)). This information highlights additional questions concerning the implementation of projects that can only be answered effectively with the utilisation of qualitative research methods that are not included in this study.

It must be stated that these findings agree with the literature in that the acceptability of traditional brick-and-block construction is extremely high (Hamilton-MacLaren et al., 2013). Environmental advantages of timber technology are acknowledged by architectural professionals, but the implementation is low in England compared with other parts of the UK like Scotland.

\subsection{Responsibility to influence, implement and to decide on the choice of technology to be used}

It is acknowledged from the literature that architects along with structural engineers are perceived to be the likely key agents influencing the material selection process having high levels of responsibility for both the technology implementation and construction methods. However, as noted in Figure 10, architectural technologists consider themselves to be responsible for the implementation of the structural technology followed by the client/developer, engineer and architect. Given this, the data suggests that the client/developer has the largest influence over structural technology, agreeing with Ball (1999), followed by the architectural technologist as the design

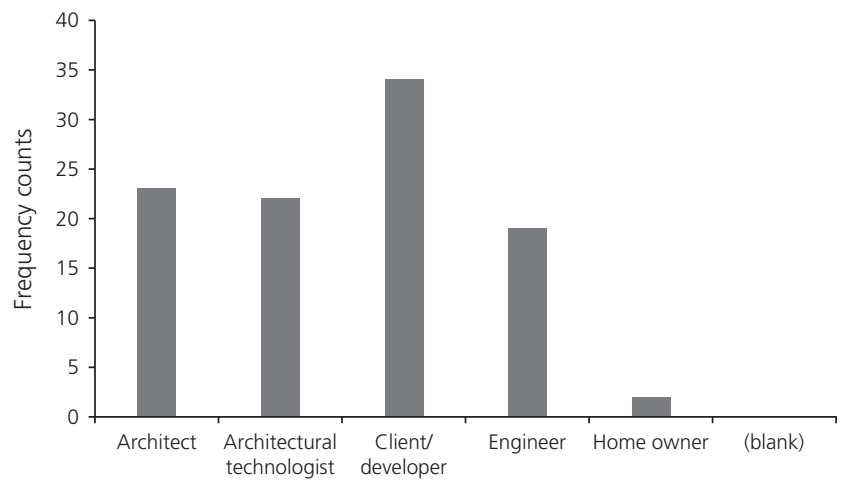

Figure 10. Highest influence over structural technology decisions

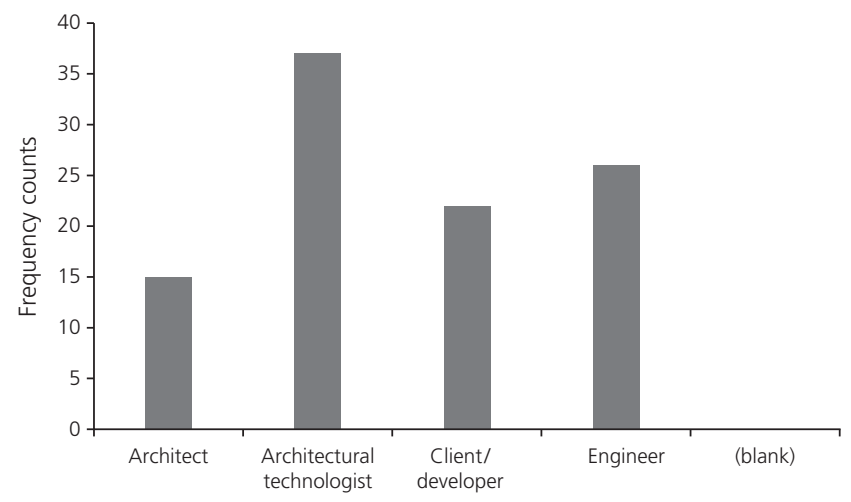

Figure 11. Responsibility for the implementation of structural technology

professional with the most influence. This conflicts with earlier assertions that architects and structural engineers are the key agents.

This trend mimics a similar response when considering the agent responsible for the initial structural decisions. It may be observed again that the client has the largest proportion of responsibility closely followed by the architectural technologist with the engineer and architect having equal standing.

In summary, other than the client/developer, this data suggests that architectural technologists consider themselves as the key agent within the design process and that they are responsible not only for the implementation of structural technology but for the overall structural decisions within the context of housing in England (Figures 10-12).

\subsection{Perception and opinion}

The research data shows clear trends as regards the perceptions and opinions that respondents have towards timber technology 
and construction within the housing market in England (Figure 13). The data displays an uncompromising indication of majority opinion within the question being answered. It should be noted that architectural technologists perceive engineers to have limited design training in timber technology and that they consider architects to have a limited understanding of the subject (Figures 13 and 14). They also agreed that mortgage lenders may have some influence over structural technology as earlier stated in GoCompare (2015) (Figure 15), but these respondents dispute the overall perception that there is

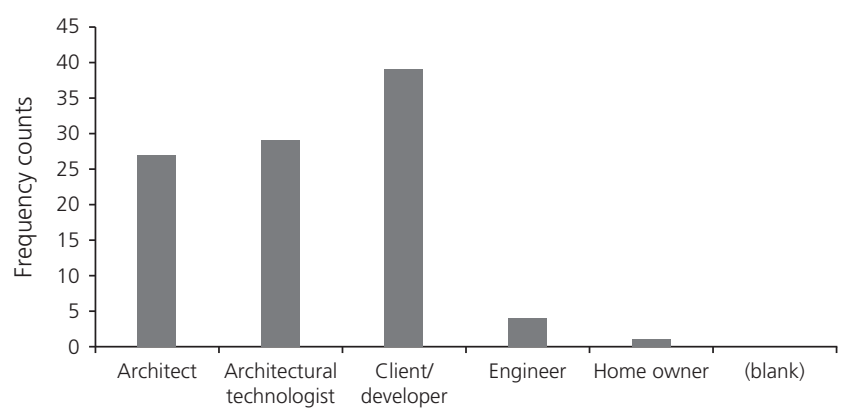

Figure 12. Responsibility for the initial structural technology decision

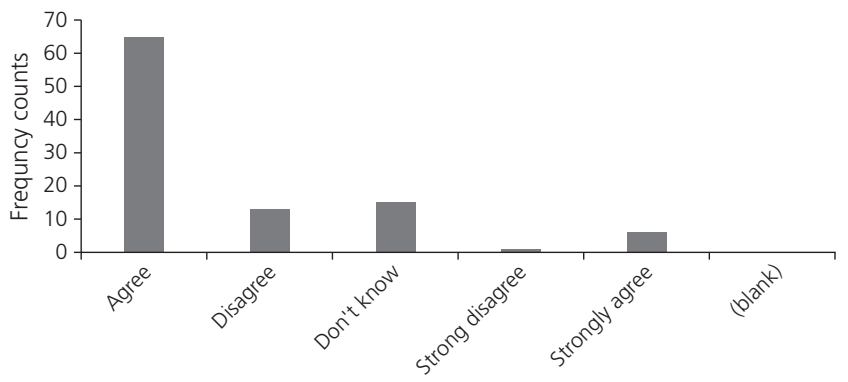

Figure 13. Limited understanding of timber technology (engineers)

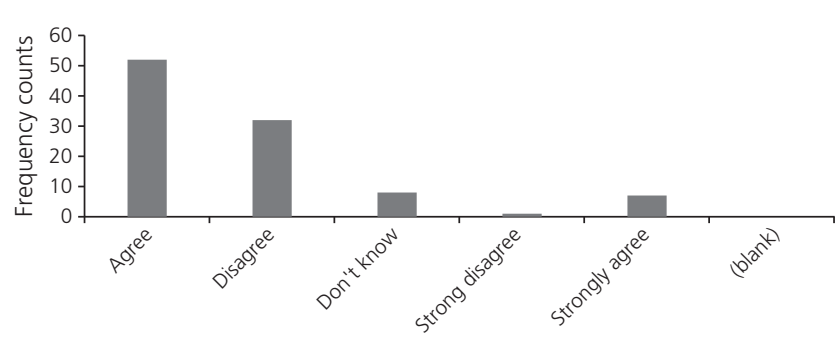

Figure 14. Limited understanding of timber technology (architect) an increased fire risk due to the use of timber (Figure 16). This poses conflicting opinions when compared with that of Mahapatra and Gustavsson (2009) and Zobel (1984). Although it is indicated that there is a lack of confidence in timber technology (Figure 17), these respondents appear to have a thorough appreciation of the timber construction method through being able to dispel the associated technical myths. Furthermore, when confronted with some of the key statements describing barriers to timber technology adoption the majority answer selection is overwhelmingly clear as indicated in Figure 18(a).

The respondents consider that timber technology allows a level of architectural freedom while improving the overall thermal and carbon dioxide performance. However, there is

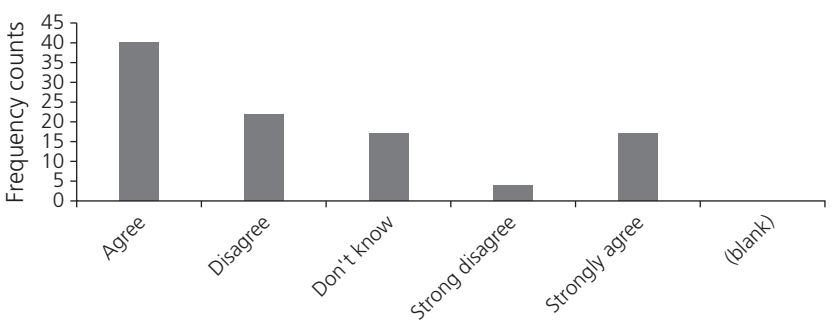

Figure 15. Mortgage lenders strong influence on the selection of structural technology

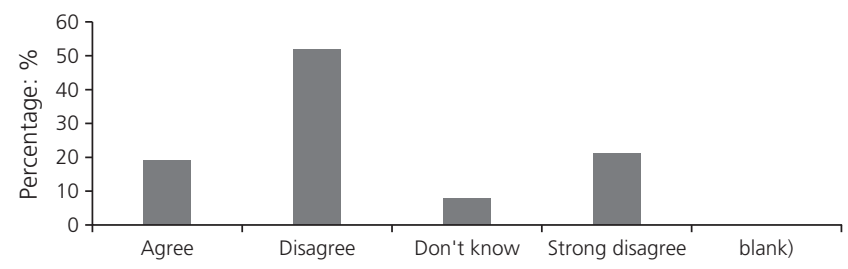

Figure 16. Timber construction technology increases fire risk

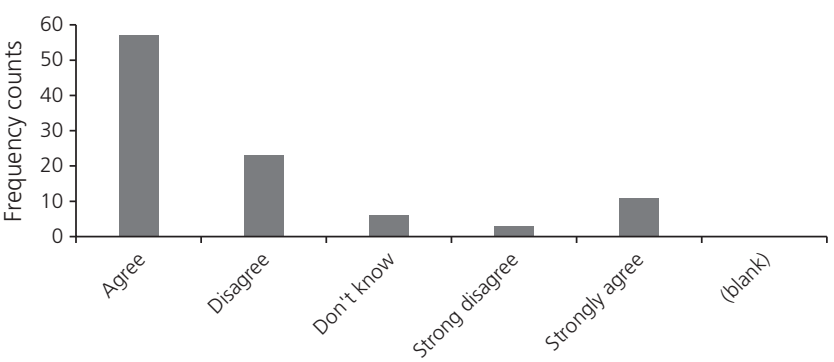

Figure 17. Lack of confidence in timber technology 
Housing infrastructure: contemporary

issues in timber adoption

Omoregie and English

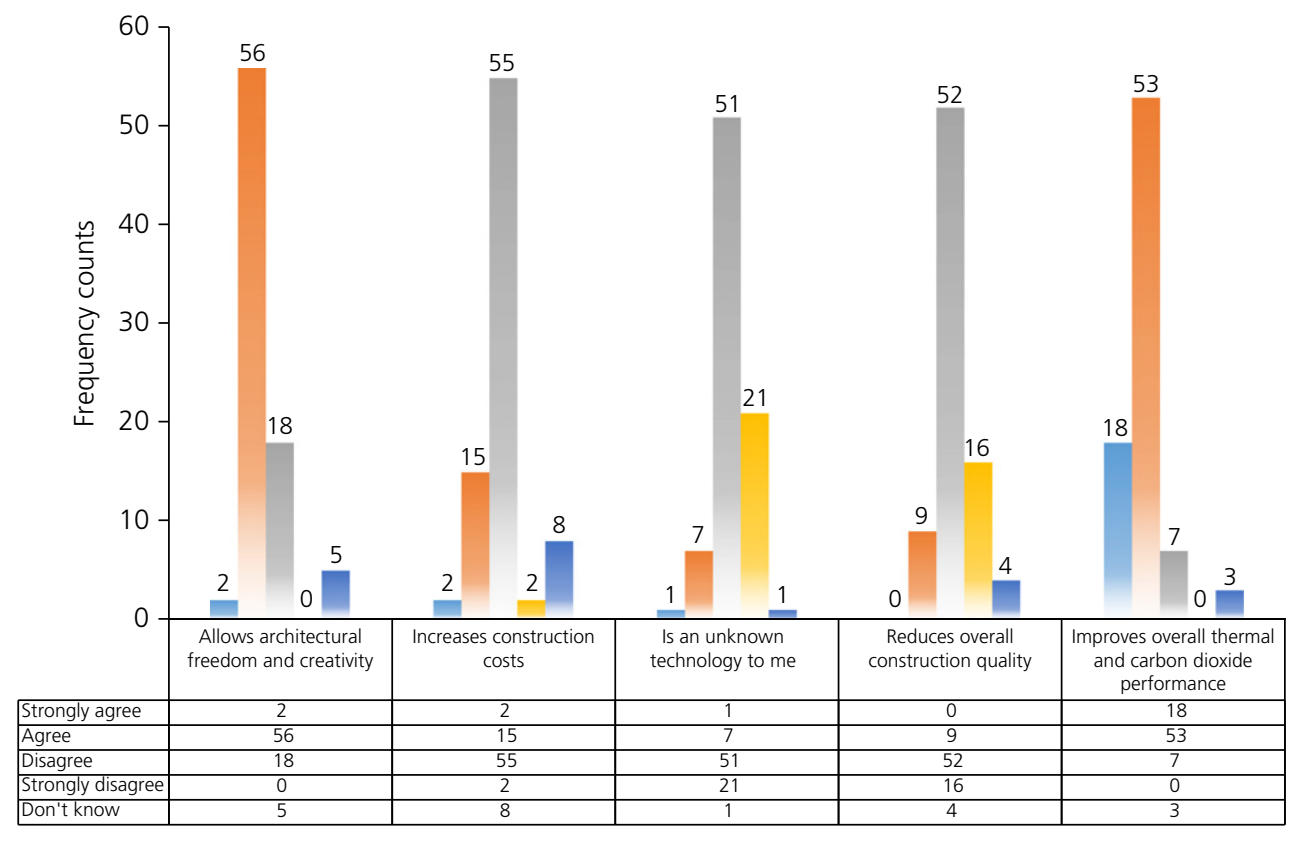

(a)

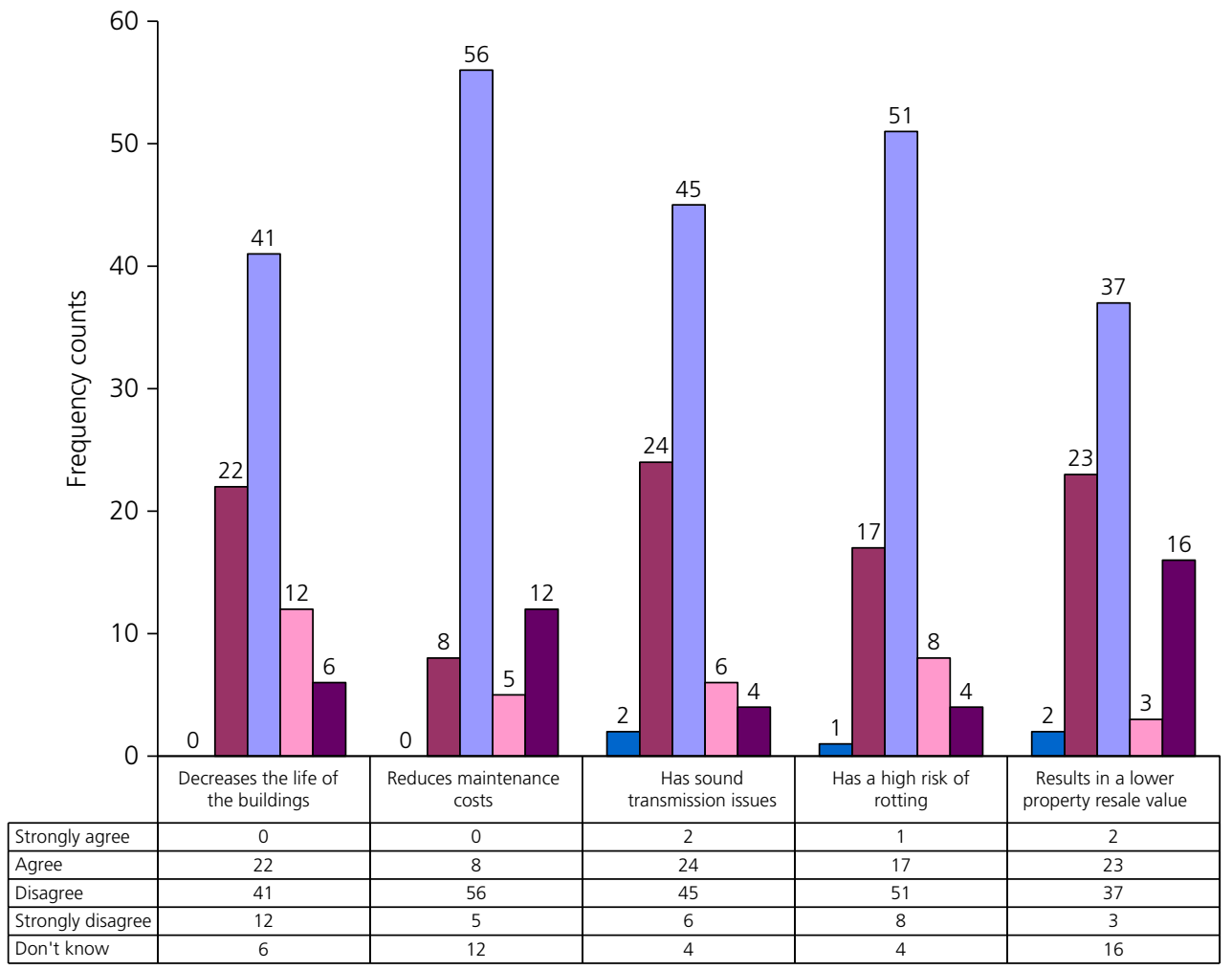

(b)

Figure 18. (a) Barriers to the adoption of timber technology (I). (b) Barriers to the adoption of timber technology (II) 
disagreement with previously cited barriers such as increased construction costs and reduced construction quality. It is also acknowledged that most of this study population disagrees with the statement indicating that timber technology is unknown to them.

Figure 18(b) further shows how architectural technologists perceive barriers that other design professionals (architects and engineers) referred to within the literature. The chart in Figure 18(b) shows that the respondents disagree with every statement linked to the perceived barrier to the adoption of timber. These include the opinion that timber technology decreases the life of buildings, increases maintenance costs, has sound transmission issues and has a high risk of rotting. In this case, the architectural technologists disagree on every account alluding to their understanding and technical appreciation of timber technology for housing applications. Throughout the entire study and data, it is incontrovertible that the lack of confidence in timber technology is one of the major barriers to the adoption of timber as a primary structural material in England. This clearly underpins the level of timber education provided in England.

Throughout the entire questionnaire, only a single element has a large 'don't know' selection by respondents. The statement that timber technology in housing results in a lower property resale value is one that may be an architectural technologist should not necessarily be aware of. However, this response does underpin the definitive selections that have gone before by establishing a clear majority selection to the overall enquiry.

\section{Conclusion and recommendations}

The aim of this study is to identify and evaluate the main barriers to the adoption of timber as a primary structural material in the English housing market. As previously illustrated, the data collection questionnaire is mapped against the research aim and subsequent objectives to achieve maximum output. Each research objective is highlighted below, and appropriate comments are made to draw attention to findings.

The first research objective - to investigate current opinions and perceptions of design professionals concerning the use of timber as primary structural material in England' - has been achieved through an extensive literature review and second through research data from fieldwork and its subsequent analysis. The research findings show that architectural technologists are experts in the field of technical building design and see themselves as the main agent in the structural technology selection process. Although these professionals are aware of the environmental benefits of timber technology within housing projects and consider it to give a level of architectural freedom and creativity, they do not recommend it as the most appropriate structural solution for housing. The reasons for this will no doubt require an in-depth study (qualitative research) to ascertain those reasons and perhaps incentives (if there are any) impacting on the decision not to adopt timber for housing in England, notwithstanding the overwhelming argument for its adoption. A staggering $60 \%$ of architectural technologists (in the research) who had experience and university education received no training in this while undertaking their undergraduate and postgraduate programmes. About $45 \%$ of the total number of architectural technologists within the study population indicated that their timber technology knowledge was gained through workplace learning with 30\% experiencing no training at all. While they perceive engineers to have limited design training in timber technology, they also consider architects to have a limited understanding of the subject. Further research may be required to understand the dynamic relationship between the architect, engineer and the architectural technologist and structural technology selection within the housing market.

The second research objective has been to identify and evaluate the main barriers to the adoption of timber as primary structural building material within England'. The study population of architectural technologists, due to their extensive practical and work-based knowledge, has dismissed a large proportion of the barriers identified in the literature review. These include the increase in construction costs, risk of timber rot, sound transmission and acoustic issues, and substandard quality and durability. It should also be noted that these respondents consider the client and the developer to have the largest influence over structural technology decisions. This may be due to public perception; however, this surely would also apply in Scotland where timber technology is heavily used. Nevertheless, the following perceived barriers have been identified as the main contributing factors for the failure in adopting timber technology within England. These are largely due to a combination of economic, cultural and psychological barriers rather than technical and durability performance.

- Lack of education - throughout the industry.

- Perceived increased maintenance costs of timber housing.

- Client and developer influence over structural technology.

- Uncertainty in property resale value.

- Overall lack of confidence in timber technology.

\subsection{Recommendations}

Given the fact that architectural technologists see themselves at the front end of the delivery and adoption of timber technology in England, it is recommended that formal university education undertaken by these professionals (architectural technologists) specifically in England should include elements of timber technology to aid future adoption and design 
Housing infrastructure: contemporary

issues in timber adoption

Omoregie and English competence. This recommendation can be augmented by the integration of sustainable and environmental design in engineering programmes. It is acknowledged that all design professionals within the construction industry should be knowledgeable about sustainable construction. It may be suggested that the benefits of timber in housing could be introduced at the pre-university level within schools and colleges in a less technical form, to create an overall increased awareness of this technology as the next generations move into professional life. This can be supported by the relevant professional institutions and public organisations through sensitising the public to the benefits timber technology provide to housing and perhaps even heritage. This recommendation may actively mitigate the negative public opinion and increase the understanding of the benefits of timber and timber technology regardless of the current negative perceptions and poor background knowledge of timber among some professionals at the front end of timber technology in England.

\section{Acknowledgements}

The authors acknowledge the staff of the School of Engineering, Construction and Science, Newcastle College and Civil Engineering Department Leeds Beckett University for the opportunity provided to undertake this study. The authors also extend their gratitude to their friend Tim Parker (itistim@ gmail.com) for proofreading the manuscript.

\section{REFERENCES}

Adams D, Payne S and Watkins C (2009) Corporate social responsibility and the UK housebuilding industry. In Corporate Social Responsibility in the Construction Industry (Murray M and Dainty A (eds)). Spon, London, UK, pp. 235-258.

Ball M (1999) Chasing a snail: innovation and house building firms' strategies. Housing Studies 14(1): 9-22.

Bayne K and Taylor S (2006) Attitudes to the Use of Wood as a Structural Material in Non-Residential Building Applications: Opportunities for Growth. Forest and Wood Products Research and Development Corporation, Victoria, Australia.

BBC (British Broadcasting Service) (2010) Timber Framed Buildings 'Fire Risk' Despite Safety Test. BBC, London, UK. See http://www.bbc. co.uk/news/uk-england-london-10645700 (accessed 03/03/2015).

Clive F (2005) The Church Explorer's Handbook. Canterbury Press, Canterbury, UK.

Creswell JW (2003) Research Design: Qualitative, Quantitative, and Mixed Methods Approaches, 2nd edn. Sage Publications, London, UK.

Dickson M and Parker D (2015) Sustainable Timber Design. Routledge, London, UK.

Dinwoodie J (2010) In Construction Materials: Their Nature and Behaviour (Illston JM and Domone PLJ (eds)). Spon Press, Oxon, UK, pp. 403-506.

Everett A and Barritt CMH (1994) Mitchells's Materials, 5th edn. Longman, London, UK.

Farrell P (2011) Writing Your Dissertation; Practical Guidance for Students of the Built Environment. Blackwell, London, UK.
Fulford R and Standing C (2014) Construction industry productivity and the potential for collaborative practice. International Journal of Project Management 32(2): 315-326.

Gibb A and Pendlebury M (2006) Glossary of Terms. Buildoffsite: Promoting Construction Offsite, London, UK.

GoCompare (2015) Timber-Framed Building Insurance. GoCompare, Newport, UK. See http://www.gocompare.com/homeinsurance/timber-framed-buildings/ (accessed 23/04/2015).

Guy NW (2006) Encyclopedia of Ancient Greece. Routledge, London, UK.

Hamilton-MacLaren F, Loveday DL and Mourshed M (2013) Public opinions on alternative lower carbon wall construction techniques for UK housing. Habitat International 37: 163-169.

Hoffmeyer P and Davidson RW (1989) Mechano-sorptive creep mechanism of wood in compression and bending. Journal of Wood Science and Technology 23(3): 215-217.

Israel GD (2013) Determining Sample Size. IFAS, University of Florida, Gainesville, FL, USA.

Johnsson H and Meiling JH (2009) Defects in offsite construction: timber module prefabrication. Construction Management and Economics 27(7): 667-681.

Kumar R (2014) Research Methodology: A Step-By-Step Guide for Beginners. Sage Publications, London, UK.

Levander E and Sardén Y (2009) Maintenance and operating costs in off-site timber frames housing. In Proceedings of 25th Annual ARCOM Conference, Nottingham, UK (Dainty ARJ (ed.)). Association of Researchers in Construction Management (ARCOM), Nottingham, UK, pp. 1183-1192.

Mackay HJ (1997) Market led house building. In Timber in Construction: Challenges for the Future, Proceedings of the BRE 75th Anniversary Seminar, in Collaboration with TRADA Technology, Watford, UK (Bravery T and Grant C (eds)). BRE Trust, Watford, UK, pp. 17-22.

Mahapatra K and Gustavsson L (2009) General Conditions for Construction of Multi-Storey Wooden Buildings in Western Europe; Wooden Eco-Building Project. Vaxjo University, Vaxjo, Sweden.

Neyman J (1937) Outline of a theory of statistical estimation based on the classical theory of probability. Philosophical Transactions of the Royal Society of London. Series A, Mathematical and Physical Sciences 236(767): 333-380.

O'Connor J, Kozak R, Gaston C and Fell D (2004) Timber use in nonresidential buildings: opportunities and barriers. Forest Products Journal 54(3): 19-28.

Ozorhon B (2012) Analysis of construction innovation process at the project level. Journal of Management in Engineering ASCE 29(4): $455-463$.

Ozorhon B (2013) Response of construction clients to low-carbon building regulations. Journal of Construction Engineering and Management ASCE 139(12): A5013001.

Palmer S (2000) Sustainable Homes: Timber Frame Housing. Hastoe Housing Association, Middlesex, UK.

Pan W, Gibb AG and Dainty AR (2008) Leading UK housebuilders' utilization of off-site construction methods. Building Research and Information 36(1): 56-67.

Roy R, Brown J and Gaze C (2003) Re-engineering the construction process in the speculative house-building sector. Construction Management and Economics 21(2): 137-146.

Self Build (2016) http://www.self-build.co.uk (accessed 15/03/2016). Strombro J and Gudmondson P (2008) Mechano-sorptive creep under compressive loading - micromechanical model. International Journal of Solids and Structures 45(9): 2420-2450. 
Taylor GD (2000) Materials in Construction: An Introduction, 3rd edn. Pearson Education, Essex, UK.

The Telegraph (2002) On the level: timber frames make rotten houses. The Telegraphy. See http://www.telegraph.co.uk/finance/property/ advice/3305395/On-the-level-timber-frames-make-rotten-houses. html (accessed 07/08/2002).

Toratti T (2008) Quality of timber construction-guidance for buildings and load bearing structures. Proceedings of the 10th World Conference on Timber Engineering, Miyazaki, Japan. Engineered Wood Products Association, Madison, WI, USA, vol. 1, pp. 438-445.

Venables T, Barlow J and Gann D (2003) Manufacturing Excellence: UK Capacity in Offsite Manufacturing, The Housing Forum. Constructing Excellence, London, UK.
Wang L, Toppinen A and Juslin H (2014) Use of wood in green building: a study of expert perspectives from the UK. Journal of Cleaner Production 65: 350-361.

Wood JGM (1993) Durability design: form, detailing, and materials. In Building the Future: Innovation in Design, Materials and Construction (Garas FK, Armer GST and Clarke JL (eds)). Spon, Brighton, UK, pp. 23-32.

Xia B, O'Neill T, Zuo J, Skitmore M and Chen Q (2014)

Perceived obstacles to multi-storey timber-frame construction: an Australian study. Architectural Science Review 57(3): 169-176.

Zobel B (1984) The changing quality of the world wood supply. Wood Science and Technology 18(1): 1-17.

\section{How can you contribute?}

To discuss this paper, please email up to 500 words to the editor at journals@ice.org.uk. Your contribution will be forwarded to the author(s) for a reply and, if considered appropriate by the editorial board, it will be published as discussion in a future issue of the journal.

Proceedings journals rely entirely on contributions from the civil engineering profession (and allied disciplines). Information about how to submit your paper online is available at www.icevirtuallibrary.com/page/authors, where you will also find detailed author guidelines. 